\title{
(t)
}

\section{ASSISTÊNCIA SOCIAL, CRISE E CONTRARREFORMAS: INFLEXÕES ENTRE O NOVO E O VELHO}

\author{
Social assistance, crises and counterreforms: inflections between the new and the old
}

\author{
Naara de Lima Campos* \\ https://orcid.org/0000-0001-5314-3599 \\ Jeane Ferraz ${ }^{* *}$ \\ https://orcid.org/0000-0001-8484-4611
}

\begin{abstract}
RESUMO
O presente artigo, resultado de pesquisa bibliográfica e documental, aporta elementos que sinalizam as tendências da função social e ideológica prática que a Política de Assistência Social brasileira assume, como parte e forma social da política social na atual fase da acumulação capitalista, sob a dominância da esfera financeira. Coloca em evidência como a PNAS responde de modo coerente frente à crise do capital em sua saída pela via neoliberal, mesmo diante das oscilações político-partidárias e das escolhas de gestão macroeconômica das últimas três décadas no país. As análises post festum, considerando quase três décadas de institucionalização do direito socioassistencial, nos fazem olhar com menos deslumbre e maior rigor conceitual, teórico, econômico e político para as inflexões da assistência social no Brasil na trilha do neoliberalismo em sua fase neoconservadora, desde o ponto de vista da economia mundial e da nossa inserção econômica periférica.
\end{abstract}

\section{PALAVRAS-CHAVE}

Crise do capital. Contrarreformas. Concepção de Assistência Social. Função ideológica.

\section{ABSTRACT}

The present paper, the result of bibliographical and documentary research, provides elements that signal the trends of the practical social and ideological function that the Brazilian Social Assistance (PNAS) assumes - as part and social shape of social policy in the current phase of capitalist accumulation - under the financial sphere dominance. It highlights how PNAS coherently responds to the capital crisis through a neoliberal way, even in the face of political party fluctuations and the choices of macroeconomic management in the last

\footnotetext{
* Assistente Social. Mestre em Política Social. Pesquisadora do Grupo de Estudos Fundamentos da Teoria Social Crítica, Serviço Social e Política Social e, do Grupo Dinheiro Mundial e Financeirização, ambos da Universidade Federal do Espírito Santo (Ufes, Vitória, Brasil). Av. Fernando Ferrari, 514, Vitória (ES), CEP.: 29075-910. E-mail: nakcampos@gmail.com.

** Assistente Social. Doutorado em Serviço Social. Professora do Departamento de Serviço Social e do Programa de Pós-Graduação em Política Social/UFES; Vice Coordenadora do Grupo de Estudos Fundamentos da Teoria Social Crítica, Serviço Social e Política Social. Universidade Federal do Espírito Santo (Ufes, Vitória, Brasil).Av. Fernando Ferrari, 514, Vitória (ES), CEP.: 29075-910.E-mail: jeaneandreiaferraz@gmail.com.
}

DOI 10.22422/temporalis.2020V2on39p11-26

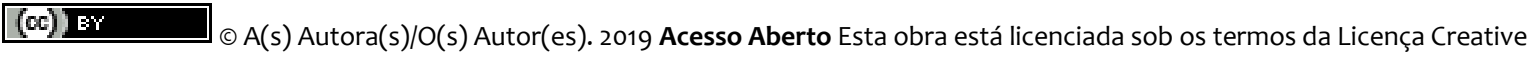
Commons Atribuição 4.0 Internacional (https://creativecommons.org/licenses/by/4.o/deed.pt_BR), que permite copiar e redistribuir o material em qualquer suporte ou formato, bem como adaptar, transformar e criar a partir deste material para qualquer fim, mesmo que comercial. O licenciante não pode revogar estes direitos desde que você respeite os termos da licença.
} 
three decades in the country. The post festum analyzes, considering almost three decades of institutionalization of social assistance law, make us look with less fascination and greater conceptual, theoretical, economic and political rigor for the inflections of social assistance in Brazil in the path of neoliberalism in its neoconservative phase, from the points of view of world economy and our peripheral economic insertion.

KEYWORDS: Crisis of capital. Counterreforms. Social Assistance Conception. Ideological function.

Submetido em: 9/2/2020.

Aceito em: 23/4/2020.

\section{INTRODUÇÃO}

A nova crise do capital no início do século XXI é explicada por CARCANHOLO (2017) pelo predomínio da disfuncionalidade da lógica do capital fictício ${ }^{1}$ para o processo de acumulação do capital total. A crise não é um evento ocasional, fortuito, exógeno ou de natureza probabilística, e sim uma manifestação inerente deste modo de produção. No momento presente, o capital fictício opera, entre outras, sob as bases da chamada securitização e das trocas dos produtos derivativos. A primeira vista ele parece funcionar autonomamente, mas sua forma implica a existência de um modus operandi do sistema mundial capitalista comandado por instituições internacionais e estatais, que propõe formas econômicas e políticas de intervenção pública específicas. Esta crise, por sua natureza, extensão e profundidade, pode ser considerada como uma crise estrutural do capital, e as medidas colocadas em marcha para seu enfrentamento são cada vez mais dolorosas para as classes trabalhadoras em escala mundial (GOMES; NAKATANI, 2015).

O conteúdo destrutivo da crise estrutural do capital reflete num agressivo processo de aviltamento de meios de existência humana, intermediados por processos cada vez mais ultrajantes de exploração, subsumindo o ser humano ao imperativo da acumulação, e expropriação de direitos conquistados historicamente pela classe trabalhadora, somada a uma mercantilização ${ }^{2}$ crescente e generalizada em todos os âmbitos ou dimensões da vida social. Assentar a discussão do capital e suas crises junto ao debate do neoliberalismo é inevitável. O neoliberalismo se dá como parte de uma estratégia econômica e ideológica capitalista para a manutenção das relações sociais visando às novas necessidades e formas de uma economia financeirizada. Segundo Harvey (2005) o neoliberalismo se tornou hegemônico como modalidade de discurso e passou a afetar tão amplamente os modos de pensamento que se incorporou às maneiras cotidianas de muitas pessoas compreenderem e viverem o mundo.

\footnotetext{
${ }^{1} \mathrm{O}$ entendimento do conceito de capital fictício em Marx só se torna possível com base no processo de autonomização das formas capital. Para análises mais aprofundadas desse fenômeno, ver (CARCANHOLO; SABADINI, 2015), (CARCANHOLO, 2017), (GOMES; NAKATANI, 2015).

${ }^{2}$ Não vamos avançar aqui em exemplos que expressem esse fenômeno. Nos reservamos apenas no cuidado de dizer que todos os processos que envolvem a reprodução das relações sociais, ou seja, a reprodução da vida material e espiritual, as formas de consciência social - jurídicas, religiosas, artísticas, filosóficas e científicas - são objetos de desejo da sagacidade do capital. Carcanholo (2017) ao explicar os atuais desdobramentos da crise do capital nos afirma "[...] a massa do capital superexplorado, como sempre, necessita de (novos) espaços de valorização. Não é casual que, neste momento, reapareça o discurso por uma maior reforma do Estado, com ampliação das privatizações, redução dos gastos públicos em setores de incidência social e o aprofundamento das reformas nos sistemas de previdência. Trata-se de criar/expandir mercados para a atuação desses capitais excedentes" (CARCANHOLO, 2017, p. 53, tradução nossa).
} 
Vamos trabalhar com a ideia de que o neoliberalismo passou por pelo menos três 3 grandes momentos em termos de estratégia e tática na América Latina. Atualmente, com o acúmulo de mais de quatro décadas de experiência da estratégia neoliberal, podemos afirmar a existência de menos duas fases com características mais marcadamente diferenciadas. A passagem de uma fase a outra pode ser constatada pelo redirecionamento do discurso, pelo volume de recursos, pelas ações voltadas para as novas prioridades dos organismos internacionais e, também, processualmente, seu desdobramento nas contrarreformas. Procuraremos demonstrar tal entre fases utilizando o caso da política de assistência social no Brasil.

As novas repercussões da crise na última década, conduziram diferentes países (centrais e periféricos) à implementação de um agressivo processo de contrarreformas - como parte das propostas de ajuste estrutural neoliberal - com implicações para a configuração e o desenvolvimento das políticas sociais, entre as quais a Assistência Social. No Brasil, sobretudo a partir dos anos 1990 temos vivido sob essa nova ordem. No contexto mais atual, ao findar a segunda década do século XXI, observamos a ascensão de um neoconservadorismo reacionário que encarna interesses reais e cada vez mais explícitos de classes.

Vivencia-se um processo de avanço à concepção de política social acorde à lógica societária capitalista, de maneira em que os indivíduos são conclamados cada vez mais a gestionarem a própria vida, mas a fazem sem qualquer dimensão de consciência de sua existência e condição de explorado. Estes elementos fortalecem concepções cada vez mais mistificadas sobre os indivíduos, e direcionam o processo de reprodução das relações sociais a caminhos cada vez mais reificados ${ }^{4}$. A Assistência Social exerce um papel importante à reprodução da ordem do capital a partir da atual concepção expressa na Política Nacional de Assistência Social, que serve de base e constructo para toda a operacionalização do Sistema Único de Assistência Social (SUAS).

O texto, para além desta introdução está divido em três sessões. Na primeira, procura-se situar a especificidade da assistência social entre os governos petistas e Temer, a partir de

\footnotetext{
3 “A primeira fase das experiências concretas neoliberais dá-se com a instauração da autocracia burguesa na América Latina. Neste momento abrem-se também as portas para que dirigentes latino-americanos, em sua maioria, com formação clássico monetarista das escolas de Chicago e Harvard, implementem as diretrizes neoliberais no continente (BATISTA, 1994). A segunda fase do neoliberalismo no continente ocorreu a partir dos 1980, (res) surgindo na região a partir de pleitos eleitorais da democracia representativa. Desde então, até o início do século XXI, a agenda política da região girou em torno do Consenso de Washington, que previa uma série de medidas para acabar com a crise da dívida externa, a estagnação econômica e os altos índices inflacionários (CASTELO, 2012). Nos anos 2000, a política econômica do Consenso foi modificada, e abriu-se para o que ficou conhecida como fase Pós Consenso de Washington, vez que não foi possível mais ignorar o alastramento da miséria na América Latina liberalizada. Os próprios organismos internacionais responsáveis pelas reformas neoliberais incluem no pacote de prerrogativas para concessões de ajuda internacional um compromisso dos estados nacionais com medidas de combate à pobreza. Esse movimento pode ser observado nos relatórios do BM a partir dos anos 2000.

4 Corforme aponta Piqueras e Dierckxensens (2018, p. 27 e 28) "As necessidades desde então, não são definidas pelo sujeito individual e menos ainda pelo sujeito coletivo, é o próprio capital que gera "desejos artificiais" que desviam das necessidades reais das maiorias. Por mais inútil ou nocivo que possa ser um valor de uso, o fato de ser vendido prova que foi valorizado e entra na "riqueza das nações". Aqui realmente chegamos ao fetichismo puro da mercadoria".
} 
uma análise, sobretudo, conceitual no contexto sócio econômico e político dessas gestões. Outra sessão segue com mais densidade na especificidade da PNAS a partir dos elementos do então chamado choque de gestão do SUAS, considerando os avanços e limites. $\mathrm{Na}$ seguinte sessão aportamos elementos que consideramos principais para discutir as medidas contrarreformistas dos governos Temer e Bolsonaro. Por último, são apresentadas algumas reflexões à guisa de conclusões.

\section{ESPECIFICIDADE DA ASSISTÊNCIA SOCIAL ENTRE GOVERNOS: QUANDO O NOVO NÃO NASCEU E O VELHO NÃO MORREU}

A Assistência Social como política pública é definida pela Constituição Federal de 1988, e regulamentada pela Lei Orgânica da Assistência Social, (LOAS), Lei nº 8.742/19935; Dez anos depois, foi aprovado o texto da Política Nacional de Assistência Social (PNAS) em 2004, e em 2005 foi criado o Sistema Único de Assistência Social (SUAS). Essas e outras regulamentações do campo socioassistencial que se seguiram, conformaram um movimento denominado por Behring (2011, p. 86) como "choque de gestão" no campo socioassistencial ${ }^{6}$.

De 1988 até o momento atual, um largo caminho foi percorrido, envolvendo discussões, divergências, mobilização de diferentes entidades e segmentos, que expressam disputas por distintos projetos societários para o campo da Assistência Social. Só é possível reconhecer esse movimento com suas contradições a partir de uma análise da processualidade histórica dessa política. Inicialmente, a assistência social após a CF, foi pensada a partir de um modelo de seguridade social previdenciário-assistencial que a situava, ao lado das políticas ligadas diretamente ao trabalho e, por essa razão, pressupunha uma lógica de altos níveis de assalariamento, sendo a assistência destinada prioritariamente aos incapazes para o trabalho. Tratava-se de um modelo fundado na lógica do seguro, em relação aos benefícios de substituição de renda, tais como aposentadorias e pensões; universal, no que tange à saúde; e seletivo em relação à assistência social, pois atenderia os inaptos para o trabalho (BOSCHETTI, 2006). No entanto, em um contexto de crise econômica em nível mundial, e com o aumento do desemprego estrutural, a Assistência Social passa a ser compreendida em termos de garantias de seguranças, com a pretensa tarefa de garantir a proteção social também daqueles capazes para o trabalho. Este ponto é central para entendermos a função que a Assistência Social foi assumindo nos momentos posteriores, quando uma nova concepção foi forjada a partir da PNAS em 2004.

É consenso entre grande parte dos balanços e análises de críticos econômicos que, do ponto de vista da economia mundial, a conjuntura internacional foi extraordinariamente favorável para o Brasil desde 2003. Mais especificamente, o ciclo ascendente da economia internacional foi causa da melhora dos indicadores conjunturais de vulnerabilidade externa dos países em desenvolvimento (FILGUEIRAS; GONÇALVES, 2007) e (NAKATANI; OLIVEIRA, 2010). Também é consenso que a economia brasileira é historicamente marcada pela forte vulnerabilidade externa nas esferas monetários-financeira, produtivo-real, tecnológica e comercial, em relação ao contexto internacional. Durante os mandatos do

5 Em 2011, a LOAS foi alterada com uma nova redação dada pela Lei ${ }^{\circ} 12.435$, cuja finalidade foi a adequação normativa às previsibilidades do SUAS.

6 Antes disso também tivemos uma PNAS aprovada em 1998 e três NOB's até a de 2012. 


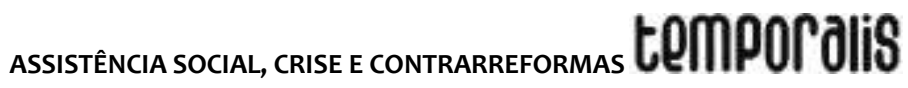

governo Lula, o Brasil passou a apresentar uma nova dinâmica no seu comércio exterior, evidenciada em reiterados e crescentes superávits na balança comercial.

A conjuntura internacional tem provocado o crescimento da demanda de matérias-primas e produtos agrícolas (commodities) e o aumento de suas cotações internacionais, com melhora nos termos de troca do Brasil (FILGUEIRAS; GONÇALVES, 2007, p. 61).

Então, não resta dúvida de que a conjuntura internacional foi a principal determinante da tendência de crescentes superávits comerciais e da melhora dos indicadores de vulnerabilidade externa conjuntural da economia brasileira.

Nos oito anos que corresponderam aos seus dois governos, Lula logrou alcançar uma taxa de crescimento anual de $4 \%$, e para tanto não realizou nenhuma reforma de consistência estrutural, de modo que o crescimento obtido foi fruto de um resultado da bonança da economia mundial que se expandiu à taxa de 5\% ao ano entre 2003 -2008, além do grandioso crescimento da China, a taxas superiores a $10 \%$, que resultou em um aumento espetacular dos preços das commodities. Foram precisamente esses elementos que permitiram ao Brasil expandir suas reservas externas, se proteger de crises externas por um dado período, reduzir seu grau de vulnerabilidade e fortalecer as finanças do Estado. Isso garantiu as condições necessárias para implementar os programas de transferência monetária, principal mote no campo da seguridade social deste governo (OLIVEIRA, 2019).

A fase ascendente, que boa parte da literatura que discute a assistência social no Brasil costuma enaltecer, durante as gestões petistas (em especial aquelas presididas por Lula) resulta de um contexto econômico externo favorável, que ao fim e a cabo, do ponto de vista de concepção e construto ideológico, a PNAS respondeu coerentemente a uma determinada forma de política social, ditada desde fora, mais especificamente pelos organismos multilaterais. No âmbito da política econômica esse ciclo ascendente começa a se esvanecer com a crise das subprimes de 2008/2009, quando o Brasil implementa uma política anticíclica em 2009/2010, incentivando o consumo para mitigar temporariamente os efeitos da crise internacional. No entanto, a crise da dívida soberana europeia e a também a reorientação do modelo de desenvolvimento chinês, reduziu a demanda por commodities, provocando grande quedas dos preços e revelando as frágeis bases do vangloriado “[...] espetáculo do crescimento [...]” (OLIVEIRA, 2019, p. 12, grifo do autor).

A presidente Dilma Rousseff assumiu o poder num quadro extremamente desfavorável, que para ser exitosa, teria duas alternativas, romper os laços com o capital e abrir caminhos para reformas mais importantes, ou ajustar adequadamente os compromissos que preservava com um modelo econômico ortodoxo do tripé macroeconômico?.

Conforme analisa Oliveira (2019) Dilma, assim como Lula não fez nem uma coisa e nem outra. Eles se aventuraram na tentativa de sustentar o crescimento com políticas econômicas alternativas equivocadas. Com isso conseguiram aumentar a erosão das bases do tripé macroeconômico deixando o país à mercê de uma grande regressão econômica.

\footnotetext{
7 Este tripé está assentado em um cambio flutuante, metas inflacionárias e geração de superávits.
} 
Por fim, uma rendição à ortodoxia econômica foi a única saída possível para reaver a confiança e o apoio do capital ao governo. Ainda assim

No governo Dilma, o PIB encolheu 8,1\% no período de 2014-2016, com uma queda do PIB per capta de $10,4 \%$, de acordo com as revisões estatísticas realizadas pelo IBGE. Foram 11 trimestres de recessão. A qual passou a ocupar o posto de segunda maior da história mais recente do País, só perdendo para a de 1981-1983 [...] (OLIVEIRA, 2019, p. 10).

Em que pese os avanços consideráveis no campo da redução da pobreza, com as políticas sociais adotadas, e em menor grau, das desigualdades, não é possível dizer o mesmo no que diz respeito ao crescimento econômico, que seria essencial como sustentáculo para a continuidade de tais políticas. Portanto, rui-se também o acordo do Estado selado com as classes dominantes para sustentar as políticas de redistribuição, já que tais políticas envolvem custos que em tese seriam assumidos por um Estado com finanças fortalecidas, a partir do crescimento econômico, para bancar tais custos.

Como as bases do crescimento não foram devidamente cimentadas com a realização de reformas estruturais, enquanto os ventos favoráveis da economia internacional sopraram a seu favor, propiciando ao Estado condições de seguir em frente com a política de inclusão, o cenário desenhado por Lula parecia uma realidade e a política econômica exemplar. Quando, no entanto, estes ventos começaram a perder força, levando a economia à desaceleração e à estagnação, com consequente queda das receitas, o Estado perdeu a condição de sustentar essa política, sem que, para isso, provocasse rachaduras na arquitetura do modelo neoliberal, do qual não se divorciara, tendo, ao sofrer vetos do capital, e sem apoio político suficiente, de render-se novamente à política ortodoxa e começar a fechar as portas do paraíso para os excluídos do sistema (OLIVEIRA, 2019, p. 13).

Quando Temer assume o poder, em virtude do golpe parlamentar seguido do impeachment da presidente Dilma, herda o quadro de resseção e alcança um quadro de estagnação. Fecha-se então um ciclo de certa ilusão de crescimento com diminuição da desigualdade social, para um estágio de estagnação econômica. Temos, portanto, até os dias atuais, uma política econômica de mesmo conteúdo ortodoxo, que seguirá com prioridade absoluta de ajuste das contas públicas para uma pretensa retomada de crescimento econômico. Iniciamos no Brasil um longo ciclo de reformas estratégicas prómercado com vistas ao aquecimento econômico em que a classe trabalhadora e as frações de classe mais empobrecidas foram as mais prejudicadas ${ }^{8}$.

As reformas desenhadas na gestão de Temer foram prenúncios para os tempos mais ardis e neoconservadores de hoje e os vindouros. Na subseção abaixo adentramos mais densamente nas transformações da assistência social, tendo este pano de fundo desenhado acima.

\footnotetext{
${ }^{8}$ Conforme os indicadores de extrema pobreza, o Brasil encerrou o ano de 2016 com 24,8 milhões de brasileiros vivendo com renda inferior a $1 / 4$ de salário mínimo por mês, o que equivale a $\mathrm{R} \$ 220,00$. Houve assim um aumento de 53\% em comparação ao ano de 2014, o que significou que $12 \%$ da população brasileira passaram a viver na miséria (INSTITUTO BRASILEIRO DE GEOGRAFIA E ESTATÍSTICA, 2017).
} 


\section{O ENTÃO CHAMADO “CHOQUE DE GESTÃO” NO SUAS: AVANÇOS E DESAFIOS}

O SUAS vem sendo construído por um processo sinuoso, com avanços, recursos, limites, possibilidades e contradições. É quase consenso no âmbito da discussão da assistência social que esta ampliou sua dimensão e capilaridade a partir dos anos 2000, ao alcançar reconhecimento e responsabilidade pública estatal de proteção social não contributiva, ao construir um novo desenho institucional na tentativa de realçar a participação da população no processo de implementação da Política.

A nova engenharia da Assistência Social, originada nos anos 2000, sobretudo a partir da PNAS de 2004, logrou avançar uma nova paisagem para essa política. Em nossa análise, a concepção que subjaz a PNAS de 2004 resguarda elementos da política de desenvolvimento humano e do combate à pobreza como parte do cumprimento da agenda dos organismos financeiros multilaterais como o Banco Mundial, o Banco Internacional para a Reconstrução e Desenvolvimento (BIRD), o Banco Interamericano de Desenvolvimento (BID) e o Fundo Monetário Internacional (FMI).

A Assistência Social neste momento passou a ser a nova peça no tabuleiro das políticas de proteção social no país, e propunha assumir, por meio de seus programas, projetos e serviços, parte considerável das mazelas deixadas pelo rastro dos ajustes das crises. Desse modo, a complexa conjuntura extrapolava a possibilidade das audaciosas pretensões para o campo institucional da Assistência Social no país. Para Mota (2009) essa política constituiu-se, nesses termos, num fetiche social, na medida em que foi invocada como solução no combate à pobreza, imprimindo a ela um direcionamento moral de enfrentamento da desigualdade.

Tratou-se de uma concepção que procurou deslocar os esforços dos sujeitos para uma esfera mais humana e, por assim dizer, individual, do desenvolvimento. Para isso, ela carrega a ideia de expandir, através da promoção de políticas públicas, as possibilidades de escolhas e oportunidades de cada indivíduo. Em larga medida, acreditamos que tal proposta difundida tomando por base a abordagem das capacidades formulada pelo economista indiano Amartya Sen ${ }^{9}$. A grande ênfase, nesse campo, tem sido a de retirar as discussões e intervenções referentes à pobreza do âmbito das relações sociais de desigualdade estrutural produzida pelo modo de produção capitalista, alocando-a nos indivíduos, já que aquela condição social é tida, nesse modo de pensar, como resultante de incapacidades individuais.

A pobreza, nesse modo de concebê-la, é discutida e definida como a ausência ou fragilidade de capacidades individuais. As políticas sociais, portanto, passam a ser orientadas aos que estão em desvantagens de capacidades, àqueles que PNAS denominam pessoas em situação de risco e em vulnerabilidade social.

Para nós, a utilização, no âmbito da execução socioassistencial, de um arcabouço de conceitos tais como capacidade, emancipação, protagonismo, risco, vulnerabilidade $e$ desenvolvimento, demarcou uma determinada concepção do direito socioassistencial no

\footnotetext{
${ }^{9}$ Tais argumentos são encontrados em análises dos referidos textos deste autor: SEN (2000a); SEN (2000b); SEN (2001) e em CAMPOS (2017).
} 
Brasil e, também, de maneira mais abrangente, reforçou uma determinada concepção de sociedade, homem e mulher. Grosso modo, uma concepção de que a sociedade que é formada por indivíduos que devam se auto cuidarem.

Neste momento, um amplo debate ${ }^{10}$ em torno das políticas de seguridade social fervilhava no país. O esforço era compreender a função e o lugar que ocupava a assistência social enquanto política pública. Foi também neste contexto que surgiu a tese de que vivíamos um processo de assistencialização dos direitos sociais no país.

Para uma política que sempre foi relegada a ações subsidiárias, assumir um papel de centralidade, por um lado, foi considerado por muitos como um grande avanço. Ao mesmo tempo em que surgiram críticas ao seu processo de expansão, como a já citada acima. Quando indagamos sobre a razão para essa expansão, temos o entendimento de que ela só pode ser explicada se levamos em consideração fatores internos e externos à realidade brasileira. Citamos aqui apenas dois: a forma como se posicionou o Brasil enquanto país periférico em temos de ajustes frente à crise; e os meandros do processo de organização para a construção dos textos e normativas do SUAS que resguardaram em seu interior uma determinada concepção de política social.

Após a consolidação dos documentos oficiais que normatizam o SUAS, uma importante função ideológica prática foi cumprida nos processos de gestão e implementação da assistência social, sobretudo no âmbito dos serviços e programas. Ao mesmo tempo em que o direito socioassistencial era garantido, uma a ideia de gestão da própria vida era consolidada.

A Assistência Social aumentou sua participação no orçamento da seguridade social quando evoluiu de 3,76\% (2000) para 9,27\% (2010). Em 2010, do montante de R\$39,1 bilhões liquidados na função 8 (assistência social) do orçamento, 39\% estiveram sob a responsabilidade da Unidade Orçamentária (UO) Ministério do Desenvolvimento Social e Combate à Fome (MDS), sendo que 92\% dos recursos foram destinados ao Programa Bolsa Família (PBF). Já na UO Fundo Nacional da Assistência Social (FNAS), que ficou responsável por $61 \%$ dos recursos da assistência social, $96 \%$ do orçamento foram liquidados no programa Proteção Social Básica, que é responsável pelo pagamento do Benefício de Prestação Continuada (BPC) e da Renda Mensal Vitalícia (RMV). (SALVADOR, 2010).

Ao analisar a execução orçamentária dos programas sob responsabilidade do MDS, constata-se de imediato que grande parcela do orçamento é destinada ao pagamento de benefícios monetários a diferentes segmentos da população em situação de pobreza PBF, BPC e RMV.

Podemos considerar que os manuais e guias de orientações da PNAS e do SUAS foram avanços ao campo da Assistência Social? No percurso para os seus processos de operacionalização, os conceitos transformados mecanicamente em processos de trabalho

\footnotetext{
${ }^{10}$ Esse debate foi travado por muitos estudiosos e gestores da área, que se debruçaram para compreender os movimentos no interior dessa política. Muitos artigos em importantes revistas científicas da área do serviço social foram publicados com este intuito. Um destaque importante do debate foi a ocasião da realização do I Seminário Nacional do/a assistente social no SUAS, realizado em 2009 pelo Conselho Federal de Serviço Social (CFESS).
} 


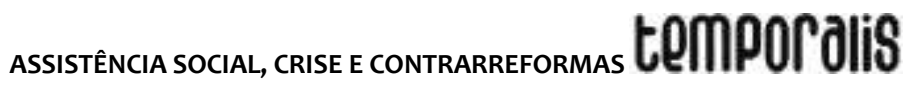

no âmbito dos espaços sociocupacionais não teriam sido reificados? A centralização dos serviços, programas e projetos no âmbito do fortalecimento à convivência familiar $e$ comunitária, não configuraram uma queda ao familismo e individualismo, incorrendo numa subjetivação das expressões das desigualdades sociais?

Pode ser que tenhamos que admitir em algum momento que construímos um verdadeiro Cavalo de Tróia, quando consolidamos uma concepção de assistência social que em alguma medida pode reforçar o individualismo, o familismo, a responsabilização dos indivíduos pelas mazelas que vivenciam, a culpabilização por não serem protagonistas, por não alçarem a tão aclamada emancipação e o desenvolvimento de capacidades.

Acreditamos que muitas dos princípios e diretrizes da PNAS, tão centrais para a construção de uma política social aliada a um projeto societário em defesa da classe trabalhadora, ficaram subsumidos ante aos já citados conceitos e suas reificações mais deletérias. Eles pareciam mais sedutores e apontavam para a criação de respostas mais fáceis ou práticas no âmbito do cotidiano e espaços de abrangência e execução da Assistência Social. Os manuais foram instrumentos que nos possibilitaram pensar, questionar e construir, ou nos fizeram imóveis e fomos seduzidos pelo canto da sereia?

Na esteira de todas essas indagações e das conclusões que apontamos acima, a assistência social entraria numa nova fase, no caminho de um novo choque que denominaremos de choque normativo reacionário, em ocasião dos últimos avanços do capital sobre os direitos dos trabalhadores em um período de crise econômica e política no país. As questões levantadas e as afirmações feitas, a princípio, podem parecer duras ou até mesmo irreais ao campo de uma política com uma capilaridade tão subsidiária no âmbito do orçamento das demais políticas. No entanto, estamos nos esforçando para voltar ao caminho e encontrar os elos perdidos que certamente não são endógenos à assistência social, mas correspondem ao movimento maior do conjunto das forças sociais e econômicas operantes.

\section{DAS MEDIDAS TEMERÁRIAS ÀS MAIS DESUMANAS E FACÍNORAS: AONDE CHEGAMOS E PARA ONDE VAMOS?}

A Assistência Social não é campo de interesse direto do mercado, ainda que parte de seu orçamento, sobretudo àquele destinado ao BPC seja um dos objetos de desejo desse deus ${ }^{11}$. Talvez, muito mais ou, ao mesmo tempo em que se pretende solapar em termos concretos um montante maior de mais-valor, esteja em curso a destruição total do caráter de direito e as garantias mínimas que havíamos alcançado no momento do choque de gestão. A ideia de direito social construída no âmbito normativo tem se desmantelado através de atos normativos infraconstitucionais e emendas constitucionais. A quem caberá a execução da política de assistência social no contento de contingenciamento orçamentário? Estaríamos sujeitos ao retorno do recente passado da filantropia e novas gestões a partir de entidades religiosas e também àquelas chamadas sem fins lucrativos?

\footnotetext{
${ }^{11}$ A vitória alcançada ao se garantir a manutenção do salário mínimo como base para o pagamento do BPC, em ocasião da reforma da previdência, recém-aprovada em 2019, é comemorada com muito entusiasmo. Insta lembrar a que a manutenção do Benefício de Prestação Continuada - BPC vinculado ao salário mínimo é uma pauta e deliberação antiga nas conferências de assistência social.
} 
Silva et al. (2019) afirmam que ao se registrar um desmonte sem precedentes dos direitos sociais, conquistados nas lutas sociais dos trabalhadores, tem-se um exitoso processo para a construção de uma "[...] contracultura de substituição do não direito pelo direito" (SILVA, 2019, p. 305).

Questionamos se algumas das perdas (orçamentárias, conceituais e ideológicas) talvez tivessem sido mais dificultadas, caso tivéssemos avançado no processo da instituição de normativas legais mais sólidas e mais ainda de um amplo e forte movimento organizado e de resistência dos usuários? Ao mesmo tempo queremos ressaltar a luta travada pelo Conselho Nacional de Assistência Social (CNAS) para garantir um orçamento minimamente compatível com os serviços a serem implementados ${ }^{12}$. O BPC ${ }^{13}$ e o Bolsa Família não puderam avançar em termos de capilaridade frente os sumários cortes orçamentários anunciados desde a EC n. 95 de $2016^{14}$.

Institui explicitamente um contexto neoconservador no qual os usuários da PNAS são amplamente atingidos, criminalizados e responsabilizados por sua situação de pobreza e por possíveis desvios na implementação dos programas sociais a eles destinados. As chamadas operações pente fino são prova cabal desse projeto neoconservador. Para Silva et al. (2019) "[...] impõem-se um projeto societário, cujo objetivo foi romper com o pacto de conciliação de classes, instituídos pelos governos petistas de Lula e Dilma (2003-2016)" (SILVA, 2019, p. 299).

Diante desse contexto, desde o governo Temer, o financiamento vem sendo contingenciado, e nesta esteira avançamos rumo à precarização do trabalho técnico e dos serviços operacionalizados no âmbito do SUAS. O cenário nos mostra certa dificuldade dos entes federados por manter ou quiçá expandir a estrutura organizativa e de serviços do SUAS.

Pari passu, os atores do SUAS seguem no esforço para manter minimamente uma estrutura e cumprir uma agenda básica. Qual o cenário hoje? Partimos de uma concepção de assistência social desde a PNAS de 2004, que claramente reclama por direitos sociais. Tais

\footnotetext{
${ }^{12}$ O Projeto de Lei Orçamentária Anual de 2019 - PLOA previa a disponibilidade de R\$ 30,899 bilhões para a área, enquanto que a proposta aprovada pelo Conselho Nacional de Assistência Social (CNAS) previa um orçamento de $\mathrm{R} \$$ 61,136 bilhões. Ou seja, uma redução de 49,46\% em relação ao proposto pelo CNAS.

13 Duas portarias ministeriais foram apresentadas para impor aos beneficiários do BPC, condicionalidades para o recebebimento, sob penalização de suspensão e corte do benefício. PORTARIA CONJUNTA N ${ }^{\circ} 3$, DE 21 DE SETEMBRO DE 2018 Dispõe sobre regras e procedimentos de requerimento, concessão, manutenção e revisão do Benefício de Prestação Continuada da Assistência Social - BPC. PORTARIA N 2.651, DE 18 DE DEZEMBRO DE 2018 que Dispõe sobre procedimentos relativos ao Benefício de Prestação Continuada - BPC cujos beneficiários não realizaram inscrição no Cadúnico no prazo estabelecido na legislação. Mais assustador ainda é o que propunha a PEC 6 da reforma da previdência no âmbito do PBC, ao intenta elevar a idade para concessão do BPC ao idoso de 65 para 70 anos e criar, para aqueles entre 60 e 69 anos, um benefício mensal no valor de $\mathrm{R} \$ 400,00$, e mais concretamente a desvinculação do salário mínimo como parâmetro para o recebimento de benefícios sociais, um direito alcançado na CF de 88 .

${ }^{14}$ No bojo do rigoroso ajuste fiscal implementado pelo governo Temer, foi aprovada a EC 95 de 2017, também denominada PEC do Teto dos Gastos Públicos, a qual institui o Novo regime Fiscal no âmbito dos Orçamentos Fiscal e da Seguridade Social da União, a vigorar por vinte exercícios financeiros. A nota técnica n. 27 (PAIVA et al., 2016), do Instituto de Pesquisa Econômica Aplicada (IPEA) apontava uma tendência de perda de recursos da assistência social de 199 bilhões em 10 anos, e de 868,5 bilhões em 20 anos para a política que resguarda o orçamento do BPC e PBF.
} 
direitos que pretensamente instituídos no âmbito normativo legal foram desmantelados através dos atuais atos normativos infraconstitucionais e emendas constitucionais, e não sabemos como se dará a continuidade das ações do SUAS. Tudo isso em meio às barreiras impostas pela EC 95, pela Lei 13.467 de 2017, também chamada de reforma trabalhista ${ }^{15}$, já em curso, e também pela recém-aprovada Reforma Previdenciária, juntamente a um pacote mais avançado de corte de gastos que a equipe econômica concebe como desvinculação orçamentária. Sobre essa última lança, é expressivo o discurso de Rogério Marinho, Secretário do setor de Previdência e Trabalho "Vamos abrir mão do sistema solidário de repartição, vamos ingressar num sistema de risco de mercado" 16 .

Quando analisamos os rumos, os caminhos para o cenário atual, através das muitas portarias interministeriais, resoluções do CNAS e decretos governamentais publicizados no sitio eletrônico do antigo Ministério de Desenvolvimento Social (MDS), transformado recentemente para Secretaria Especial de Desenvolvimento Social, podemos constatar pelo menos três grandes redirecionamentos de ordem programática para a Assistência Social desde 2016, até o momento atual. Um processo de expansão da focalização em determinados segmentos populacionais para o acesso ao SUAS com ênfase na primeira infância; novas bases com caráter mais restritivo para acesso ao BPC e ao Bolsa família; e a partir disso um verdadeiro ataque moralizante sobre a pobreza e os pobres no Brasil regido por um fundamentalismo moral religioso sem precedentes em nossa recente e frágil democracia. Importantes resistências, mesmo que limitadas na esfera democrática institucional dos conselhos de políticas, têm se notado ao acompanharmos as movimentações e manifestações do $\mathrm{CNAS}^{17}$. Em contraposição a esse afago, voltamos a afirmar que recentes atos normativos são lançados para fragilizar e romper tais estruturas democráticas e de controle social conquistadas em 1988.

É impossível negar que uma expressão cabal da emergência de uma nova era para o campo socioassistencial tem sido a implementação desde 2016 do chamado "Programa Criança Feliz" ${ }^{18}$, parte de um componente central e em vias de ser substitutivo à lógica da PNAS a partir de uma sobreposição enquanto um programa de governo ao próprio sistema estatal.

As críticas que tecemos a este programa são incontáveis. Desde a sua forma de apresentação, ao seu processo de construção e implementação no âmbito dos municípios. Tal programa se contrapõe à universalidade ao recortar a primeira infância na faixa de 0 a 3 anos, além de fragilizar o Estatuto da Criança e do Adolescente (ECA) na defesa integral dos direitos da infância. Isso para não falar que ele abriu grandes portas à chamada cultura

\footnotetext{
${ }^{15}$ Para análise dos impactos dessa contrarreforma ver (STOCCO; CAMPOS; NAKATANI; BORGES, 2019).

16 Trecho do discurso do Rogério Marinho - Secretário do setor de previdência e trabalho, proferido no seminário A Nova Economia Liberal, ocorrido dia 15 de março, no Centro Cultural FGV, pela iniciativa da FGV Projetos e o Centro de Economia Mundial da FGV.

17 Em 2016, o CNAS através da RESOLUÇÃO N 13, DE 19 DE AGOSTO DE 2016 que institui o Grupo de Trabalho para discussão da Proposta de Emenda Constitucional 241 de 2016, que altera o Ato das Disposições Constitucionais Transitórias, para instituir o Novo Regime Fiscal e também aprovou a RESOLUÇÃO N ${ }^{\circ} 22, D^{2}$ 14 DE DEZEMBRO DE 2016 onde, posicionou-se contrário à Proposta de Emenda à Constituição - PEC n 287 , de 2016 (então reforma da previdência proposta ainda em 2016).

18 Importante análise encontra-se em Sposati (2017). RESOLUÇÃO № 4, DE 21 DE OUTUBRO DE 2016. Pactua as ações do Programa Criança Feliz no Sistema Único de Assistência Social -SUAS, a ser instituído nos termos do $\$ 1^{\circ}$ do art. 24 da Lei $n^{\circ} 8.742$, de 7 de Dezembro de 1993.
} 
do primeiro-damismo, um retrocesso inadmissível a essa altura da política de assistência. Acelerou também uma tendência que já observávamos há tempos, considerando a precarização dos processos formativos no âmbito da educação superior. O programa é implementado por profissionais de nível médio, sem domínio técnico para a compreensão do contexto da realidade social na qual se inserem as famílias e crianças atendidas.

Então, o que de novo e assustador temos nos tempos atuais? Um avanço da barbárie capitalista produzida em tempos de crises e contrarreformas que não faz questão de ser velado. O acordo entre os desiguais proposto pela política de conciliação de classes implementadas durante o governo petista, já se coloca como desinteressante aos novos governos. Tal acordo virou motivo de chacota em vários discursos da equipe econômica do atual governo, que disparou ataques gratuitos contra os direitos sociais alcançados, questionando as suas reais necessidades.

Podemos dizer que o projeto societário com força política e econômica, hoje, que se desponta resguarda bases numa ortodoxia neoliberal ${ }^{19}$ bastante assustadoras e sufocantes para a classe trabalhadora em todas as dimensões e organizações da vida. Segue fala do presidente da Fundação Getúlio Vargas, Carlos Ivan Simonsen Leal, na companhia de parte da equipe econômica do atual governo. "Você não sai de trinta anos de social democracia em um ciclo de commodities que jogamos a poeira". Você não sai de uma cultura de direitos adquiridos onde você jamais disse contra quem os direitos eram adquiridos contra quem, contra todos nós. Jamais foi dito no Brasil contra quem os direitos eram adquiridos, e foram contra todos nós "os capitalistas".

\section{CONCLUSÃO}

Acredita-se que o chamado choque de gestão experienciado pela assistência social no Brasil, sobretudo nos anos 2000, que teve suas ações sobredeterminadas pelas agências internacionais, encobrem as determinações ideológicas ${ }^{20}$ e políticas a favor da reprodução de propostas integracionistas, de conciliação de classes, visando certa reforma social aliançada ao neoliberalismo. Mas, mais do que isso, essa direção política e ideológica de condução da PNAS que datou os governos petistas construiu elementos de base importantes para os atuais redirecionamentos da política de assistência social na atualidade pós-golpe parlamentar. Neste novo contexto de acirramento da barbárie, a chamada conciliação de classes é um horizonte cada vez mais longínquo. Estamos longe de aclamar essa saída. Esta conciliação de classes claramente não é nada benéfica para os trabalhadores, já que entendemos não ser possível servir a dois senhores ao mesmo tempo.

\footnotetext{
19 Trecho do discurso do presidente da FGV, proferido no seminário A Nova Economia Liberal, ocorrido dia 15 de março, no Centro Cultural FGV, pela iniciativa da FGV Projetos e o Centro de Economia Mundial da FGV. Disponível em: https://fgvprojetos.fgv.br/eventos/nova-economia-liberal.

20 Em qualquer período histórico existem ideologias conflitantes e estas ideologias possuem uma implicação consciente e prática necessárias para a organização das principais classes da sociedade em confronto. As formas ideológicas orientadas para a prática são a possibilidade para que os homens se tornem conscientes desse confronto e lutem (MÉSZÁROS, 2004).
} 
É premente o entendimento de que na atuação com as políticas públicas e sociais, necessária é a crítica e deciframento dos determinantes econômicos, que singularizam a contraditoriedade entre a condição de direito conquistado pelos trabalhadores e de sua refuncionalização como processo de coesão à ordem e aquietação da pugna que submerge as lutas sociais. Portanto, como devir ser, o horizonte está localizado para uma assistência social que socializa e não individualiza os sujeitos. Esse é o lugar que deve ocupar a assistência social nos processos do desenvolvimento do ser humano, que passa pela formação de uma nova consciência social.

A EC 95 que institui um Novo Regime Fiscal (NRF) com brutal corte de direitos sociais; a plena expansão do Programa Criança Feliz; a contrarreforma trabalhista em curso desde 2017; e a contrarreforma da previdência através da PEC 6 de 2019, retratam as transformações mais atuais que resvalam no campo sociassistencial. Os impactos dos retrocessos políticos e econômicos se interpõe ao chamado avanço ocorrido com "choque de gestão", a partir do arcabouço conceitual criado como sustentáculo das práticas socioassistenciais. Um verdadeiro ataque normativo-jurídico despontou de forma acelerada para fazer ruir qualquer pretensa intencionalidade de dar ao capital uma face mais humana no Brasil atual, intermediada pela PNAS.

A política de assistência social, em que pese os avanços de gestão, não logrou construir um espaço de organização popular e de consciência política de seus usuários e, portanto, está num processo de desmonte em sua concepção e ações no trânsito dos governos petistas ao governo Temer, e segue a um movimento de desmonte, que conforma de modo bastante coerente aos interesses e necessidades dessa nova fase do capitalismo em crise. Nos parece que se edifica um novo choque na assistência social. Agora poderíamos chamar de choque normativo reacionário, e nos importa avançar no entendimento dos impactos do novo fenômeno para o campo da assistência social, que é o próprio campo das relações sociais nas quais estamos inseridas neste momento histórico.

O cenário nos mostra a dificuldade dos entes federados por manter a estrutura organizativa dos serviços, programas e projetos do SUAS, e mais grave que tudo isso, impera o constructo ideológico erigido desde os anos 2000 com mudanças, todavia mais nefastas. É chegada a hora de olhar com cuidado e atenção para essa trajetória, vez que ao fazer política pública precisa-se atentar para as intencionalidades, sabedores de que se pode, a partir dela, cumprir a função social de determinada concepção de sociedade de homem e de mulher.

Laçamos mão de uma frase elucidadora do ex-presidente Luís Inácio Lula da Silva para entendermos parte do processo histórico vivido nos últimos anos. "Eu não estou acima da Justiça. Se eu não acreditasse na Justiça, eu não tinha feito um partido político. Eu tinha proposto uma revolução nesse país" ${ }^{21}$ (LULA, 2017, não paginado). Para nós a realidade posta é a de que o projeto de conciliação de classes - não cabe mais - e a tentativa dessa conciliação produziu um grande dano político irreparável para a classe trabalhadora até este momento. Somente o movimento organizado dos trabalhadores e trabalhadoras ao longo do tempo, pode nos trazer alentos.

\footnotetext{
${ }^{21}$ Discurso proferido em 12 de julho de 2017, após a primeira condenação do ex-presidente.
} 
Nos termos dos documentos enviados pelo Banco Mundial para o Brasil -, "Um ajuste justo: análise da eficiência e equidade do gasto público no Brasil" (2017) e "Por um ajuste justo com crescimento compartilhado: uma agenda de reformas para o Brasil” (2018), - revelase a necessidade imperiosa do capital em cumprir sua agenda. Estamos longe de termos avançado na organização da luta coletiva, e a prova cabal é o avassalador avanço conservador e a matança generalizada dos povos. Somam-se a isso os limites da esquerda no campo institucional. Se podemos afirmar diante de tempos tão difíceis que vivemos algo de esperançoso, é o fato de entendermos que as condições objetivas de respostas do capital à sua própria crise podem permitir aos trabalhadores um processo de aprofundamento de consciência de classe, já que estamos pagando a conta desde muito.

\section{REFERÊNCIAS}

BATISTA, Paulo Nogueira. O consenso de Washington: a visão neoliberal dos problemas latino-americanos. 1994. Disponível em:

http://professor.pucgoias.edu.br/SiteDocente/admin/arquivosUpload/17973/material/Cons enso\%20de\%20Washington.pdf. Acesso em: 20 jan. 2020

BEHRING, E. R. Balanço Crítico do SUAS e o Trabalho do/a Assistente Social. In: CONSELHO FEDERAL DE SERVIÇO SOCIAL. Seminário Nacional 0 trabalho do/a Assistente Social no SUAS. Brasília (DF), 2011. p. 84-95.

BOSCHETTI, Ivanete. Seguridade social e trabalho: paradoxos na construção das políticas de previdência e assistência no Brasil. Brasília (DF): Letras Livres, 2006.

BRASIL. Ministério do Desenvolvimento Social e Combate à Fome. Política Nacional de Assistência Social (PNAS). Norma Operacional Básica (NOB/SUAS). Brasília, 2004.

CAMPOS, Naara de Lima. As políticas sociais no capitalismo contemporâneo e o pensamento de Amartya Sen: pontos de convergência. In: ENCONTRO NACIONAL DE POLÍTICA SOCIAL, 5., ENCONTRO INTERNACIONAL DE POLÍTICA SOCIAL, 12., 2017, Vitória. Anais [...]. Vitória: Universidade Federal do Espírito Santo, 2017.

CARCANHOLO, Marcelo Dias. Dependencia superexplotación del trabajo y crisis: uma interpretação desde Marx. Madrid: Maia edições, 2017.

CARCANHOLO, Reinaldo A.; SABADINI, Mauricio de S. Capital fictício e lucros fictícios. In: GOMES, Helder (ed.). Especulação e lucros fictícios: formas parasitárias da acumulação contemporânea. São Paulo: Outras Expressões, p.125-159, 2015.

CASTELO, Rodrigo. O novo desenvolvimentismo e a decadência ideológica do pensamento econômico brasileiro. Revista Serv. Soc. Soc., São Paulo, n. 112, p. 613-636, out./dez. 2012.

FILGUEIRAS, Luiz Antonio Mattos.; GONÇALVES, Reinaldo. A economia política do governo Lula. Rio de Janeiro: contraponto.2007 
GOMES, Helder; NAKATANI, Paulo. A natureza e as contradições da crise capitalista. In: GOMES, Helder (ed.). Especulação e lucros fictícios: formas parasitárias da acumulação contemporânea. São Paulo: Outras Expressões, p. 247-276, 2015.

HARVEY, David. Condição Pós-Moderna. Parte II. São Paulo: Loyola, 2005.

LULA fala após ser condenado pelo juiz Sérgio Moro. Estadão, São Paulo, 13 jul. 2017. Disponível em: https://politica.estadao.com.br/ao-vivo/lula-coletiva. Acesso em: maio 2019.

INSTITUTO BRASILEIRO DE GEOGRAFIA E ESTATÍSTICA. Síntese dos indicadores sociais: uma análise das condições de vida da população brasileira. Rio de Janeiro, 2017.

MARQUES, R. M.; FERREIRA, Mariana Robeiro Jansen. O Brasil sob a nova ordem: a economia brasileira contemporânea. São Paulo: Saraiva, 2010.

MÉSZÁROS, István. Poder da ideologia. São Paulo: Boitempo, 2004.

MOTA, Ana Elizabete. A centralidade da assistência social na seguridade social brasileira nos anos 2000. In: MOTA, Ana Elizabete. $\mathbf{O}$ mito da assistência social: ensaios sobre Estado, política e sociedade. 3. ed. São Paulo: Cortez, 2009.

NAKATANI, Paulo.; OLIVEIRA, Fabrício Augusto de. Política Econômica Brasileira de Collor a Lula: 1990-2007. In: MARQUES, R. M.; FERREIRA, Mariana Robeiro Jansen. O Brasil sob a nova ordem: a economia brasileira contemporânea. São Paulo: Saraiva, 2010.

OLIVEIRA, Fabrício Augusto de. Governos Lula, Dilma e Temer: do espetáculo do crescimento ao inferno da recessão e da estagnação (2003-2018). 1. ed. Rio de Janeiro: Letra Capital, 2019.

PAIVA, Andrea Barreto de et al. O novo regime fiscal e suas implicações para a política de assistência social no Brasil. Brasília (DF), 2016. (Nota Técnica, n. 27). Disponível em: https://www.abrasco.org.br/site/wpcontent/uploads/2016/09/nt_27_IPEA_regime_fiscal_assistencia_social.pdf. Acesso em: dez. 2019.

PIQUERAS, Andrés; DIERCKXSENS, Wim (orgs.). O Capital frente ao seu declínio. São Paulo: Expressão Popular, 2018.

SALVADOR, Evilásio. Fundo público e seguridade social no Brasil. São Paulo: Cortez, 2010.

SEN, Amartya. Igualdade de quê?. In: Desigualdade reexaminada. Rio de Janeiro: Record, 2001. Capítulo 1, p. 43-68.

SEN, Amartya. A perspectiva da liberdade. In: Desenvolvimento como liberdade. São Paulo: Companhia das Letras, 2000a. Capítulo 1, p. 27-50. 
SEN, Amartya. Pobreza como privação de capacidades. In: Desenvolvimento como liberdade. São Paulo: Companhia das Letras, 200ob. Capítulo 4, p. 109-134.

SILVA, Maria Ozanira Silva e et al.. A política de assistência social na conjuntura brasileira de desconstrução de direitos e de desmonte da seguridade social: 2016/2018. In: SILVA, Maria Ozanira Silva e (Coord.) O Sistema Único de Assistência Social (SUAS) no Norte e Nordeste realidades e especificidades. São Paulo: Cortez, 2019.

SPOSATI, Aldaísa. Transitoriedade da felicidade da criança brasileira. Serv. Soc. Soc., São Paulo, n. 130, p. 526-546, set./dez. 2017.

STOCCO, Aline Faé; CAMPOS, Naara de Lima; NAKATANI, Paulo; BORGES, Rodrigo Emmanuel Borges. Gestão estatal da força de trabalho no Brasil: Economia política de uma reforma. In: ANUARIOS de estudios políticos latino-americanos. Universidad Nacional de Colombia: Clacso, 2019. p. 81-104.

\footnotetext{
Naara Campos sistematizou o artigo a partir de estudos e revisão bibliográfica que subsidiam investigações que vêm sendo realizados em sua pesquisa de doutoramento.

Possui graduação em Serviço Social pela Universidade Federal do Espírito Santo (UFES) (2009), Mestrado (2012) em Política Social pela UFES, e está em estágio de Doutoramento em Política Social pela UFES, (Bolsista CAPES). Experiência de Doutorado Sanduíche no Instituto de Políticas y Bienes Públicos (IPP) del Consejo Superior de Investigaciones Científicas (CSIC) Espanha (2017/2018), e na Universidad Complutense de Madrid, Espanha, Departamento de Economia Aplicada (2017/2018). Atualmente é representante de base da Comissão de Orientação e Fiscalização do Exercício Profissional (COFI) do Conselho Regional de Serviço Social CRESS $17^{\circ}$ Região. Pesquisadora do Grupo de Estudos Fundamentos da Teoria Social Crítica, Serviço Social e Política Social (INTERFACES) do Grupo Estudos sobre Dinheiro Mundial e Financeirização da Universidade Federal do Espírito Santo. Tem atuação técnica e desenvolve pesquisas na área de Serviço Social, Política Social e Política de Assistência Social.
}

Jeane Ferraz co-autora, sistematizou o artigo realizando revisão bibliográfica, indicando referências e adensando a discussão sobre a temática.

Possui graduação em Serviço Social pela Universidade Federal do Espírito Santo (1990), mestrado em Serviço Social pela Universidade do Estado do Rio de Janeiro (2005) e doutorado em Serviço Social pela Universidade do Estado do Rio de Janeiro (2014). Professora adjunto do Departamento de Serviço Social e do Programa de Pós-Graduação em Política Social da Universidade Federal do Espírito Santo. Tem experiência na área de Serviço Social, com ênfase em Política Social e Trabalho, atuando principalmente nos seguintes áreas: fundamentos do serviço social, sistema único de assistência social - suas, políticas sociais, financiamento e controle democrático. É vice-coordenadora e líder no Diretório do Cnpq do INTERFACES - Grupo de Estudos dos Fundamentos da Teoria Social Crítica, Serviço Social e Política Social. Membro titular representante da UFES no Núcleo de Educação Permanente do SUAS/ES (NUEP/ES). Foi presidente do Conselho Regional de Serviço Social $17^{\mathrm{a}}$ Região - gestão 2005-2008 e tesoureira da Associação Brasileira de Ensino e Pesquisa em Serviço Social - ABEPSS - Gestão 2017-2018. 